\title{
Testing to Prevent Colon Cancer: How Rural Community Members Took on a Community-Based Intervention
}

\author{
Ned Norman ${ }^{1}$ \\ Shirley Cowart ${ }^{1}$ \\ Maret Felzien ${ }^{1}$ \\ Connie Haynes ${ }^{1}$ \\ Mike Hernandez $z^{1}$ \\ Mary Petra Rodriquez ${ }^{1}$ \\ Norab Sanchez ${ }^{1}$ \\ Sergio Sanchez ${ }^{1}$ \\ Katby Winkelman ${ }^{1}$ \\ Steve Winkelman ${ }^{1}$ \\ Rebecca Van Vorst ${ }^{2}$ \\ Linda Zittleman ${ }^{3}$ \\ Jobn M. Westfall ${ }^{3}$ \\ 'High Plains Research Network Community \\ Advisory Council, Denver, Colorado \\ ${ }^{2}$ Deyta, Louisville, Kentucky \\ ${ }^{3}$ Department of Family Medicine, High \\ Plains Research Network, University of \\ Colorado, Denver, Colorado
}

Conflicts of interest: authors report none.

\section{CORRESPONDING AUTHOR}

John M. Westfall, MD, MPH

Department of Family Medicine

High Plains Research Network

University of Colorado

Mail Stop F496, AO1

Aurora, CO 80045

jack.westfall@COHealthOp.org

\begin{abstract}
Participatory research can elevate research relevance and effectiveness. The literature contains few first-hand descriptions of community members engaged in research. In 2003, the High Plains Research Network convened a Community Advisory Council (CAC) that quickly began providing input, feedback, innovation, and dissemination efforts. After receiving a participatory research grant from the Centers for Disease Control and Prevention aimed at increasing colorectal cancer screening, the CAC participated in an intensive training on colon cancer prevention and spent 6 months developing a locally relevant intervention-Testing to Prevent Colon Cancer. CAC members participated in all aspects of the research including intervention messaging, survey design, recruitment, implementation, analysis and interpretation of data, and dissemination of results including presentations at national venues and coauthoring manuscripts. Our experience attests to the power of participatory research in efforts to improve health outcomes.
\end{abstract}

Ann Fam Med 2013;568-570. doi:10.1370/afm.1586.

\section{ORIGINS OF THE COMMUNITY ADVISORY COUNCIL}

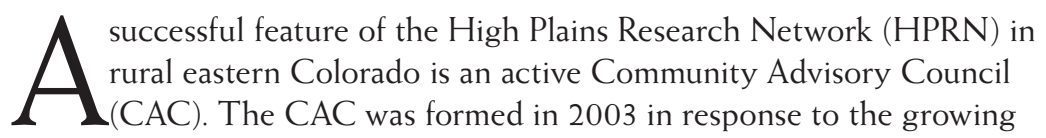
interest in engaging patients and the broader community in research, as well as the Agency for Healthcare Research and Quality's requirement for practice-based research networks to have a mechanism to obtain "advice and feedback from the communities of patients" served by the network. CAC members include local farmers, a rancher, an elementary school teacher, a hardware store owner, a dental assistant, a junior college faculty member, a home health worker, retirees, and high school students. We joined the group when we received a personal call from the HPRN director and agreed to participate as long as we believed our community was benefitting from the work. We choose research topics, and researchers or funders occasionally present research opportunities. We decide whether or not to participate, and we are not afraid to say no. We have coauthored manuscripts, presented at national research meetings, and led workshops on community engagement.

Members of the HPRN CAC are frequently asked how we are "really" involved in the projects. What do we do? What ideas do we provide? Although we have participated in more than a dozen research studies over the past 10 years, this commentary describes one example of our involvement in a community-based study in rural Colorado. This is our story. ${ }^{1}$

\section{TESTING TO PREVENT COLON CANCER}

The HPRN research team brought this research opportunity to us, asking, "What do you think about this idea...?" Although increasing awareness of colon cancer had not been on our top-10 priority list, we quickly 
saw that the project met our biggest goal: helping our communities to be healthier. We learned that colon cancer is the second leading cause of cancer death in the United States. ${ }^{2}$ We discovered that screening rates in Colorado were low; only $36 \%$ of eligible adults reported fecal occult blood testing in the past 2 years, and $49 \%$ reported having ever had a sigmoidoscopy or colonoscopy. ${ }^{3}$ We decided it would be a good first project to pursue as we all learned how to do participatory research together. We have since worked on many other projects from our priority list. Sometimes we work on our community ideas, other times, we work on ideas from a clinician, researcher, or funder.

The intervention Testing to Prevent Colon Cancer was funded by the Centers for Disease Control and Prevention (CDC) and used a community-based participatory research approach to develop and test a message and distribution model aimed at increasing colon cancer screening. Community participation and leadership were a key feature in this project. The CAC attended an intensive "boot camp" to learn about colon cancer. We then designed the intervention messages, materials, and implementation strategies, deciding not only what to say but how to say it. The group changed the language to be more simple and direct, while maintaining medical accuracy. Examples include using "testing" instead of "screening" and "colon cancer" in place of "colorectal cancer." The CAC assisted with analysis, interpretation of results, and dissemination of the findings. ${ }^{4-8}$

\section{MONTHS OF BOOT CAMP TRANSLATION}

The first part of the boot camp was to learn about colon cancer through an in-depth presentation on epidemiology, pathology, and screening methods. We even spent time on a sigmoidoscopy simulator. Our group had no idea that colon cancer was the second leading cause of cancer deaths and that it was preventable. This "schooling" was essential to get everyone on equal footing in understanding colon cancer. This session developed a common language, purpose, and focus for the project. The very medically detailed presentation taught us an important lesson regarding health literacy. It made us aware of the gap that we need to bridge between our local community and the medical community. Our community group distilled and translated the knowledge we gained in boot camp into 4 key messages: (1) colon cancer is the second leading cause of cancer death in the United States, (2) colon cancer is preventable, (3) testing is worth it, and (4) talk to your doctor today.

The second part of the boot camp was brainstorming. We talked about how to get people interested in this topic without offending anyone. We wanted to stress the importance of screening for colon cancer.
All of us were fully engaged, effusive with ideas. Over time, we changed how we approached the topic and message. We started out using terms learned from boot camp but eventually realized that we were uncomfortable with the medical language. We moved toward language we could understand. Our discussions became more conversational and collaborative. We recall long discussions regarding specific language and wording. We felt that our message needed to be short and clear. We had to focus on our primary audience... and this rural population never really talks about topics in depth but banters about anything and everything. If we could give them something to banter about, we were in!

Developing materials was the part of the project that the group naturally gravitated to. We started brainstorming on poster paper. We listed every conceivable way to reach people in a rural community. Between meetings, we had short conference calls to continue the process. It took time to really solidify our products. One of the first things agreed on was the newspaper articles. We wanted to tell the story of local people. We decided to ask a local physician and a community member to give local community talks.

The 3 most important characteristics of our language and materials were authenticity, authenticity, and authenticity. Materials couldn't be slick and corporate. It was important that they be simple, realistic, and truthful. We believed it was key that our materials be personal. As community members, we knew that we paid more attention to information if it involved someone we knew personally. We read stories in the paper not because of what they are about but because of who they are about. We also knew that the people with real community power weren't necessarily the bank presidents, mayors, and chief executive officers who are usually tapped for these kinds of projects. Our knowledge of our communities allowed us to find the people who would resonate locally. Honestly, it was this authentic voice and design that made this project strong. If you don't know the culture of the community, it is difficult to know how to reach them and very easy to make mistakes and even offend people. We made the language and materials appropriate for our rural population. Colon cancer is much easier to talk about in our community now than it was before this intervention. We created a video about our experience (Supplemental Appendix 1, available at www. annfammed.org/content/11/6/568/suppl/DC1).

\section{COMMUNITY INVOLVEMENT MADE THE DIFFERENCE}

We are surprised by how involved we all were in this project. The CAC had opportunity for input, a lot 
of respect, and as much responsibility as each of us wanted. We all attended the 4 research meetings and participated in the 8 conference calls. This process helped us to understand participatory research and that even though the process is slow, it works.

We were also surprised by the reactions from community members. For one thing, even though we were apprehensive to address colon cancer with the people we were recruiting, they never hesitated to say yes. They wanted to help. Once the conversations began, participants have continued to banter about colon cancer ever since. So many people went from being uninformed and uninterested to being motivated to talk to their physician about colon cancer.

At first we were uncertain we could produce the results everyone wanted. Having an institution such as the CDC fund this project and having a CDC representative at meetings added to this uncertainty. The boot camp and guided brainstorming helped us to focus. After we completed the messages, we experienced that tension between research and community action: impatience. The community had an idea, a purpose, and a calling; we were ready for action now. The research side was barely ready to take the next baby step. We all gave a little and moved forward. We are much more patient now, and the researchers try to work a bit faster too.

As we like to advise researchers, when you ask community members to work with you, you had better buckle up and step aside. Our community-based intervention engaged hundreds of community members, reached more than $65 \%$ of the intended target audience, and strengthened a group of committed community participants. Engaging the CAC allowed the intervention to grow from and into our community. Many volunteers we recruited became advocates for the intervention and extended the reach and depth of the message. Because of the CAC, the communities took ownership of their own intervention (Supplemen-

tal Figure 1, available at www.annfammed.org/ content/11/6/568/suppl/DC1).

We were active in disseminating information about this study. The CAC requested and helped create a summary of the process, the intervention, and the results, which were published in local newspapers, shared with physicians and clinics, disseminated on the radio, and handed out at local health events. Presenting our research findings at local events closed the loop and reignited the conversation. Formal scientific presentations were made at state, national, and international meetings. Several CAC members are coauthors on manuscripts. One served on a public health thesis committee for a student working on this project. We received the Colorado Public Health Association's
Sabin Award for outstanding contribution to public health. Recently, HPRN received a grant to fund Testing to Prevent Colon Cancer in southeast Colorado.

People ask us how we were involved. We participated fully; we owned this project! Our experience shows how powerful participatory research can be in designing and implementing interventions to improve population health, and can serve as a motivating example for others.

To read or post commentaries in response to this article, see it online at www.annfammed.org/content/11/6/568.

Key words: participatory research; practice-based research; health knowledge, attitudes, practice; health campaigns; colon cancer; public health

Submitted July 24, 2012; submitted, revised, March 20, 2013; accepted April 2, 2013.

Funding support: This publication was supported by Cooperative Agreement 5 U48 DP000054-03 from the Centers for Disease Control and Prevention and by Rocky Mountain Prevention Research Center SIP 20-04 and the NIH/NCRR Colorado CTSI grant UL1 RR025780.

Disclaimer: This article's contents do not necessarily represent the official views of the Centers for Disease Control and Prevention or the National Institutes of Health.

Acknowledgments: We thank the following people who provided extra help in developing and implementing Testing to Prevent Colon Cancer: the more than 200 residents of eastern Colorado who helped with this project; Garry Haynes; Saeid Ahmadpour, MD; Arlene Harms; Denise Hase; James Miller, MD; Kindra Mulch, RN; Grace Linn, MA; Steve Coughlin, PhD, MPH; and Fred Grover, MD.

\section{References}

1. Westfall JM, Zittleman L, Sutter C, et al. Testing to Prevent Colon Cancer: results from a rural community intervention. Ann Fam Med. 2013;11(6):500-507.

2. Centers for Disease Control and Prevention (CDC). Colorectal (Colon) Cancer Incidence Rates. 2005. http://www.cdc.gov/Features/ dsColorectalCancer/. Accessed May 20, 2011.

3. Colorado Department of Public Health and the Environment. Colorado Colorectal Cancer Screening 2003-2004 BRFSS. 2005. http:// www.cdphe.state.co.us/scripts/htmsql.exe/cohid/brfssfrm1.hsql. Accessed May 20, 2011.

4. Coughlin SS, Costanza ME, Fernandez ME, et al. CDC-funded intervention research aimed at promoting colorectal cancer screening in communities. Cancer. 2006;107(5 Suppl):1196-1204.

5. Young WF, McGloin J, Zittleman L, West DR, Westfall JM. Predictors of colorectal screening in rural Colorado: testing to prevent colon cancer in the High Plains Research Network. J Rural Health. 2007;23(3):238-245.

6. Zittleman L, Emsermann C, Dickinson M, et al. Increasing colon cancer testing in rural Colorado: evaluation of the exposure to a community-based awareness campaign. BMC Public Health. 2009;9:288.

7. Rim SH, Zittleman L, Westfall JM, Overholser L, Froshaug D, Coughlin SS. Knowledge, attitudes, beliefs, and personal practices regarding colorectal cancer screening among health care professionals in rural Colorado: a pilot survey. J Rural Health. 2009;25(3):303-308.

8. Overholser L, Zittleman L, Kempe A, et al. Use of colon cancer testing in rural Colorado primary care practices. J Gen Intern Med. 2009;24(10):1095-1100. 